\title{
Erratum to: Acinetobacter refrigeratoris sp. nov., Isolated from a Domestic Refrigerator
}

\author{
Guangda Feng $\cdot$ Songzhen Yang $\cdot$ Yonghong Wang • \\ Qing Yao $\cdot$ Honghui Zhu
}

Published online: 25 November 2014

(c) Springer Science+Business Media New York 2014

\section{Erratum to: Curr Microbiol (2014) 69:888-893 \\ DOI 10.1007/s00284-014-0669-6}

The original version of this article unfortunately contained an error in title. The etymology of species name was incorrect based on The International Code of Nomenclature of Prokaryotes. The correct epithet is refrigeratoris (re.fri.ge.ra.to'ris. N.L. gen. n. refrigeratoris of a refrigerator, from which the type strain was isolated). The correct title is "Acinetobacter refrigeratoris sp. nov., Isolated from a Domestic Refrigerator". In the species description, the deposition numbers of type strain in different Culture collection center are the same as the original paper.

The online version of the original article can be found under doi:10. 1007/s00284-014-0669-6.

G. Feng $\cdot$ S. Yang $\cdot$ Y. Wang $\cdot$ H. Zhu $(\bowtie)$

State Key Laboratory of Applied Microbiology Southern China, Guangdong Provincial Key Laboratory of Microbial Culture Collection and Application, Guangdong Open Laboratory of Applied Microbiology, Guangdong Institute of Microbiology, Building 59th, 100 Xianlie Zhong Road, Guangzhou 510070,

China

e-mail: zhuhh@gdim.cn

S. Yang $\cdot$ Q. Yao

College of Horticulture, South China Agricultural University,

Guangzhou 510642, China 